\title{
Effects of reconstructive surgery for left ventricular anterior aneurysm on ventriculoarterial coupling
}

\author{
F Fantini, G Barletta, A Toso, M Baroni, M Di Donato, M Sabatier, V Dor
}

\begin{abstract}
Objective-To investigate left ventricular elastance (Emax) and effective arterial elastance (Ea) in postinfarction left ventricular aneurysm and evaluate their role in left ventricular function improvement after endoventricular circular patch plasty (EVCPP). Ventriculoarterial coupling has never been studied in these patients.
\end{abstract}

Patients-22 consecutive patients (49 to 73 years) with left ventricular anterior aneurysm.

Methods-Haemodynamic studies were done before and two weeks after EVCPP. Ventriculography was performed during atrial pacing (100 beats/min). Pressurel volume loops were analysed and derived parameters measured. Emax was estimated by applying the "single beat" method. Ea was calculated as end systolic pressure/stroke volume.

Results-Left ventricular volumes and Ea decreased after surgery: end diastolic volume index from mean (SD) 155 (53) to 106 (29); end systolic volume index from 112 (51) to $62(30) \mathrm{ml} / \mathrm{m}^{2}$ (both $\left.\mathrm{p}<0.0001\right)$; Ea from $1.65(0.70)$ to $1.39(0.41) \mathrm{mm} \mathrm{Hg} / \mathrm{ml}$ $(p=0.04)$. Ejection fraction and Emax increased, without significant changes in stroke volume and work. The decrease in Ea was directly correlated with its preoperative value. The time interval between left ventricular pressure upstroke and peak systolic pressure decreased, from 237 (39) to 191 (41) ms $(p<0.0001)$, paralleling morphological changes in pressure tracings.

Conclusions-After EVCPP, ventriculoarterial coupling improves because of the fall in Ea caused by end systolic pressure reduction. The improvement is related to aortic pressure waveform changes and improved relaxation.

(Heart 1999;81:171-176)

Keywords: left ventricular aneurysm; left ventricular function; arterial elastance; ventriculoarterial coupling

University of Florence M Baroni

Cardiothoracic Centre of Monaco, Monaco

M Sabatier

V Dor

Correspondence to: Professor Fantini. email: f.fantini@dfc.unifi.it

Accepted for publication 2 September 1998 arterial elastance (Ea). ${ }^{1}$ Ea, measured as the ratio between end systolic pressure and stroke volume, ${ }^{12}$ is the value of ventricular pressure developed for each millilitre of blood transferred to the arterial system, and it incorporates both the mean and the pulsatile components of arterial load. In the normal heart ventricular elastance (the energy source) and Ea (the load) are strictly coupled to maximise the amount of energy transferred from the source to the load.

Recent studies ${ }^{45}$ have shown that patients with cardiac dysfunction, with or without overt congestive heart failure, have an abnormally increased arterial elastance. The mismatch between depressed left ventricular function and increased Ea could be reverted towards normal by means of inotropic ${ }^{5}$ or afterload reducing drugs. ${ }^{7}$

The benefits of surgical repair of left ventricular aneurysm on cardiovascular function have long been debated. While linear suture after resection of the aneurysmal sac gave inconsistent results, ${ }^{8}$ endoventricular circular patch plasty repair (EVCPP) induced a consistent improvement in left ventricular pump function, ${ }^{9}$ mainly owing to the reduction of wall tension caused both by the reduction of volumes and the restoration of a more advantageous chamber shape. ${ }^{10}$ Arterial elastance and ventriculoarterial coupling have not been evaluated in postinfarction left ventricular aneurysm with depressed function. In this study patients with anterior aneurysm and depressed left ventricular function, who were submitted to endoventricular patch plasty reconstruction, were evaluated haemodynamically before and after surgery to determine the changes in ventriculoarterial coupling and arterial elastance.

\section{Methods}

Twenty two consecutive patients (mean age 59 years, range 49 to 73 ) with postinfarction anterior left ventricular aneurysm who underwent EVCPP $^{11}$ at the Cardiothoracic Centre of Monaco between April 1992 and May 1993 were studied. All patients were in sinus rhythm and had had anterior myocardial infarction. The median time since the myocardial infarction was 12.5 months. Patients with significant mitral regurgitation were excluded. Cardiac catheterisation and angiography were performed preoperatively and before discharge (about two weeks after the intervention) in all patients. Clinical and angiographic data are given in table 1.

Aortic pressure was measured by a fluid filled catheter inserted in the aortic root 
Table 1 Clinical and angiographic characteristics

\begin{tabular}{|c|c|c|c|c|c|c|c|c|c|}
\hline \multirow[b]{2}{*}{ Patient } & \multirow{2}{*}{$\begin{array}{l}\text { Age } \\
\text { (years) }\end{array}$} & \multirow[b]{2}{*}{ Sex } & \multirow{2}{*}{$\begin{array}{l}\text { Months } \\
\text { from MI }\end{array}$} & \multirow{2}{*}{$\begin{array}{l}\text { Preop } \\
\text { NYHA }\end{array}$} & \multicolumn{4}{|c|}{ Coronary lesions } & \multirow{2}{*}{$\begin{array}{l}\text { Graft } \\
\text { number }\end{array}$} \\
\hline & & & & & $L M$ & $L A D$ & $C x$ & $R C$ & \\
\hline 1 & 65 & M & 60 & III & - & $\mathrm{Y}$ & $\mathrm{Y}$ & $\mathrm{Y}$ & 2 \\
\hline 2 & 63 & M & 4 & IV & - & $\mathrm{Y}$ & $\mathrm{Y}$ & - & 2 \\
\hline 3 & 49 & $M$ & 15 & II & - & $\mathrm{Y}$ & $\mathrm{Y}$ & - & 2 \\
\hline 4 & 73 & M & 2 & III & - & $\mathrm{Y}$ & - & - & 1 \\
\hline 5 & 66 & $M$ & 9 & II & - & $\mathrm{Y}$ & $\mathrm{Y}$ & $\mathrm{Y}$ & 3 \\
\hline 6 & 60 & M & 10 & III & - & $\mathrm{Y}$ & $\mathrm{Y}$ & - & 2 \\
\hline 7 & 69 & M & 108 & II & $\mathrm{Y}$ & $\mathrm{Y}$ & - & - & 2 \\
\hline 8 & 64 & $M$ & 5 & II & - & $\mathrm{Y}$ & - & - & 1 \\
\hline 9 & 54 & M & 48 & IV & $\mathrm{Y}$ & $\mathrm{Y}$ & $\mathrm{Y}$ & - & 4 \\
\hline 10 & 49 & $M$ & 2 & II & $\mathrm{Y}$ & $\mathrm{Y}$ & $\mathrm{Y}$ & - & 2 \\
\hline 11 & 49 & M & 21 & III & - & $\mathrm{Y}$ & - & - & 1 \\
\hline 12 & 53 & M & 4 & IV & - & $\mathrm{Y}$ & - & $\mathrm{Y}$ & 1 \\
\hline 13 & 57 & M & 24 & III & - & $\mathrm{Y}$ & $\mathrm{Y}$ & $\mathrm{Y}$ & 3 \\
\hline 14 & 57 & M & 60 & II & - & $\mathrm{Y}$ & $\mathrm{Y}$ & - & 1 \\
\hline 15 & 62 & $M$ & 2 & III & - & $\mathrm{Y}$ & - & - & 1 \\
\hline 16 & 63 & $M$ & 48 & IV & - & $\mathrm{Y}$ & $\mathrm{Y}$ & - & 2 \\
\hline 17 & 59 & $\mathrm{~F}$ & 21 & IV & - & $\mathrm{Y}$ & $\mathrm{Y}$ & - & 2 \\
\hline 18 & 60 & $M$ & 108 & III & - & $\mathrm{Y}$ & $\mathrm{Y}$ & $\mathrm{Y}$ & 3 \\
\hline 19 & 55 & M & 5 & IV & - & $\mathrm{Y}$ & - & - & 2 \\
\hline 20 & 49 & $M$ & 8 & II & - & $\mathrm{Y}$ & - & - & 1 \\
\hline 21 & 64 & M & 3 & IV & - & $\mathrm{Y}$ & $\mathrm{Y}$ & - & 1 \\
\hline 22 & 62 & M & 96 & IV & - & $\mathrm{Y}$ & - & $\mathrm{Y}$ & 2 \\
\hline
\end{tabular}

$\mathrm{Cx}$, circumflex coronary artery; LAD, left anterior descending coronary artery; LM, left main coronary artery; MI, myocardial infarction; NYHA, New York Heart Association functional grade; $\mathrm{RC}$, right coronary artery; $\mathrm{Y}$, presence of critical coronary lesion.

through a radial artery. Cardiac output was measured before angiography by means of the thermodilution method using a Swan-Ganz catheter. Left ventricular angiography $\left(30^{\circ}\right.$ right anterior oblique projection) was performed before coronary arteriography with an $8 \mathrm{~F}$ micromanometer tipped catheter and filmed at 50 frames/second. Heart rate was fixed at 100 beats/min during angiography by atrial pacing to avoid differences in heart rate dependent haemodynamic variables such as ejection fraction and Ea.

Frame by frame left ventricular silhouettes were manually traced and digitised using uniform sampling every $0.1 \mathrm{~mm}$; left ventricular pressures were digitised at 1000 samples/ second. Ventricular volumes were calculated using the Chapman monoplane method. ${ }^{12}$

A computer program was used to construct interpolated left ventricular pressure-volume loops and the following variables were automatically calculated from pressure tracings: maximum left ventricular systolic pressure, left ventricular end diastolic pressure, maximum rate of rise of left ventricular pressure $(\mathrm{dP} /$ dtmax), maximum rate of decay of left ventricular pressure ( $\mathrm{dP} / \mathrm{dtmin})$, and the time constant of left ventricular pressure decline during isovolumic relaxation $(\tau) \cdot{ }^{13}$ The time intervals between end diastole and maximum left ventricular systolic pressure ( $t$-peak) and between end diastole and $\mathrm{dP} / \mathrm{dtmax}(\mathrm{t}-\mathrm{dP} /$ dtmax) were automatically measured. From left ventricular volume data, the following variables were calculated: end diastolic volume index (EDVI), end systolic volume index (ESVI), stroke volume index (SVI = EDVI ESVI), and ejection fraction (SVI/EDVI).

As a measure of contractile function, the end systolic pressure-volume relation (ESPVR) was estimated from steady state single beat pressure-volume loops, by applying the method of Senzaki et al. ${ }^{14}$ Briefly, assuming a linear model, ESPVR was defined by a volume axis intercept $\left(\mathrm{V}_{0}\right)$ and a slope (left ventricular elastance). Elastance curves, defined as $\mathrm{E}(\mathrm{t})=\mathrm{P}(\mathrm{t}) /\left[\mathrm{V}(\mathrm{t})-\mathrm{V}_{0}\right]$ and normalised both by amplitude and time to peak amplitude, were found $^{14}$ to remain consistent during the first $25 \%$ to $35 \%$ of contraction, despite different underlying cardiac disease, contractility, loading conditions, and heart rate. Hence, in that study, a composite $\mathrm{E}_{\mathrm{N}}\left(\mathrm{t}_{\mathrm{N}}\right)$ curve was obtained by averaging several $\mathrm{E}\left(\mathrm{t}_{\mathrm{N}}\right) /$ Emax curves, where $\mathrm{t}_{\mathrm{N}}=\mathrm{t} / \mathrm{tmax}$, tmax being the time from the $\mathrm{R}$ wave to the maximum $\mathrm{P} / \mathrm{V}$ ratio, first assuming $\mathrm{V}_{0}=0$. We computed the volume intercept from the equations defining $\mathrm{E}(\mathrm{t})$ and $\mathrm{E}$ (tmax), hereafter called Emax:

$$
\begin{array}{r}
\mathrm{V}_{0}=\left[\mathrm{P}_{\mathrm{N}}\left(\mathrm{t}_{\mathrm{N}}\right) \mathrm{V}(\operatorname{tmax})-\mathrm{V}\left(\mathrm{t}_{\mathrm{N}}\right) \mathrm{E}_{\mathrm{N}}\left(\mathrm{t}_{\mathrm{N}}\right)\right] / \\
{\left[\mathrm{P}_{\mathrm{N}}\left(\mathrm{t}_{\mathrm{N}}\right)-\mathrm{E}_{\mathrm{N}}\left(\mathrm{t}_{\mathrm{N}}\right)\right]}
\end{array}
$$

where $\mathrm{P}_{\mathrm{N}}\left(\mathrm{t}_{\mathrm{N}}\right)=\mathrm{P}\left(\mathrm{t}_{\mathrm{N}}\right) / \mathrm{P}(\mathrm{tmax})$, and $\mathrm{E}_{\mathrm{N}}\left(\mathrm{t}_{\mathrm{N}}\right)$ was obtained from non-linear interpolation of Senzaki's data. From $V_{0}$ it was possible to obtain $\operatorname{Emax}=\mathrm{P}(\mathrm{tmax}) /\left[\mathrm{V}(\mathrm{tmax})-\mathrm{V}_{0}\right]$.

A refinement estimation was accomplished by iteratively redetermining tmax at the time of maximum $\mathrm{P} /\left(\mathrm{V}-\mathrm{V}_{0}\right)$ and then recalculating $\mathrm{V}_{0}$ until no significant volume variation was found.

Emax was indexed for body surface area in $\mathrm{mm} \mathrm{Hg} / \mathrm{ml} / \mathrm{m}^{2}$.

End systolic pressure (ESP) was defined as left ventricular pressure at tmax. Stroke work was calculated from the integral of left ventricular pressure-volume loop.

$\mathrm{Ea}(\mathrm{mm} \mathrm{Hg} / \mathrm{ml})$ was calculated as the ratio between ESP and stroke volume. ${ }^{1}$

Work efficiency was evaluated by calculating the potential work index (PWI) according to the formula proposed by Rooke and Feigl ${ }^{15}$ :

PWI $=4.08 \times 10^{-4} \times(\mathrm{sAOP} \times \mathrm{HR})+3.25 \times$ $10^{-4} \times(0.8 \mathrm{sAoP}-0.2 \mathrm{dAoP}) \times(\mathrm{HR} \times \mathrm{SV} / \mathrm{BW})+$ 1.43

where sAoP and dAoP are systolic and diastolic arterial pressure, $\mathrm{HR}$ is the heart rate, and $\mathrm{BW}$ is body weight in $\mathrm{kg}$. This formula, derived from an experimental work, has recently been applied in a clinical investigation. ${ }^{6}$ Chamber efficiency was calculated as the ratio between stroke work and potential work index.

The index of peripheral vascular resistance (PVRI, dyne.s $/ \mathrm{cm}^{5} / \mathrm{m}^{2}$ ) was calculated as mean blood pressure $\times 80 /$ cardiac index.

\section{STATISTICAL ANALYSIS}

Data are reported as mean (SD). Comparisons among preoperative and postoperative haemodynamic data were performed by using paired $t$ test. Correlations were determined by calculating Pearson's coefficient of correlation. A p value of $<0.05$ was considered statistically significant. Data were analysed by SPSS for Windows statistical package version 7.0 (SPSS Inc, Chicago, Illinois, USA).

\section{Results}

Preoperative and postoperative haemodynamic data are given in table 2 . The scatter plots of ventricular volumes, LVEF, and LVEDP preoperatively and after surgery are shown in fig 1 . The preoperative study showed severe left ven- 
Table 2 Haemodynamic data before and after surgery

\begin{tabular}{|c|c|c|c|c|c|c|c|c|c|c|c|c|}
\hline & $\begin{array}{l}E D V I \\
\left(\mathrm{ml} / \mathrm{m}^{2}\right)\end{array}$ & $\begin{array}{l}E S V I \\
\left(\mathrm{ml} / \mathrm{m}^{2}\right)\end{array}$ & $\begin{array}{l}S V I \\
\left(\mathrm{ml} / \mathrm{m}^{2}\right)\end{array}$ & $\begin{array}{l}\text { LVEF } \\
(\%)\end{array}$ & $\begin{array}{l}S W(g / m / \\
\left.\min / m^{2}\right)\end{array}$ & $S W / P W I$ & $\begin{array}{l}\text { PVRI (dyne.s/ } \\
\left.\mathrm{cm}^{5} / \mathrm{m}^{2}\right)\end{array}$ & $\begin{array}{l}\text { LVEDP } \\
(m m \mathrm{Hg})\end{array}$ & $\begin{array}{l}\mathrm{Ea}(\mathrm{mm} \\
\mathrm{Hg} / \mathrm{ml})\end{array}$ & $\begin{array}{l}\operatorname{Emax}(\operatorname{mm} \\
\left.\mathrm{Hg} / \mathrm{ml} / \mathrm{m}^{2}\right)\end{array}$ & $V_{o}(m l)$ & Ea/Emax \\
\hline Preoperative & $155(53)$ & $112(51)$ & $44(13)$ & $30(12)$ & $52(23)$ & $0.33(0.15)$ & $1613(327)$ & $18(5)$ & $1.65(0.70)$ & $1.37(1.13)$ & $2(59)$ & $4.53(6.56)$ \\
\hline After surgery & $106(29)$ & $62(30)$ & $44(10)$ & $44(13)$ & $59(28)$ & $0.52(0.18)$ & $1558(454)$ & $14(4)$ & $1.39(0.41)$ & $1.73(1.11)$ & $-10(43)$ & $1.86(2.83)$ \\
\hline $\mathrm{p}$ Value & 0.0001 & 0.0001 & NS & 0.0001 & NS & 0.0001 & NS & 0.005 & 0.04 & 0.05 & NS & 0.01 \\
\hline
\end{tabular}

Values are mean $(\mathrm{SD})$.

Ea, effective arterial elastance; EDVI, end diastolic volume index; Emax, maximum systolic ventricular elastance; ESVI, end systolic volume index; LVEDP, left ventricular end diastolic pressure; LVEF, ejection fraction; PVRI, peripheral vascular resistance index; SVI, stroke volume index; SW, stroke work index; SW/PWI, left ventricular work efficiency; $\mathrm{V}_{0}$, intercept of Emax slope.

tricular dysfunction with markedly increased EDVI, a low ejection fraction, low Emax, high Ea, and low chamber efficiency. Ea showed an inverse correlation with chamber efficiency $(r=-0.57, \mathrm{p}<0.01)$. The ratio between arterial and ventricular elastance was increased, indicating ventriculoarterial mismatch.

After surgery, there was a marked reduction in left ventricular volumes and a significant increase in ejection fraction, without changes in mean SVI and stroke work. End diastolic pressure decreased slightly, end systolic pressure decreased, while SP did not change. PVRI did not show a significant reduction.

Ea decreased significantly, mainly because end systolic pressure decreased. The changes in Ea were related both to its preoperative values and to the postoperative improvement in the ejection fraction (thus the greatest reduction in Ea occurred in patients with higher preoperative values $(r=0.84, \mathrm{p}<0.0001$; fig 2 ) and with a greater postoperative increase in
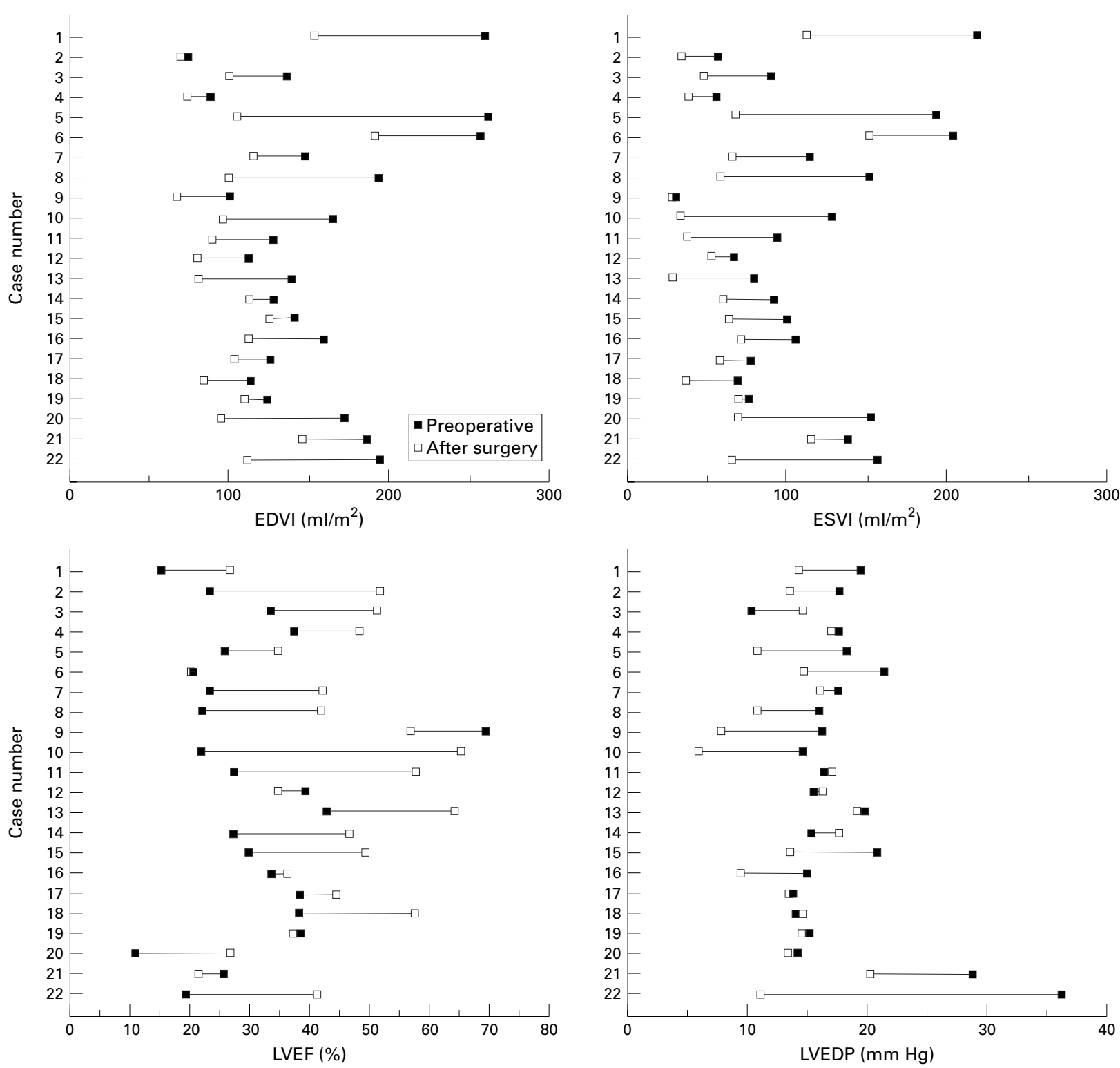

Figure 1 Scatterplots of left ventricular volumes (end diastolic volume index (EDVI); end systolic volume index (ESVI); left ventricular ejection fraction (LVEF); and left ventricular end diastolic pressure (LVEDP)). 


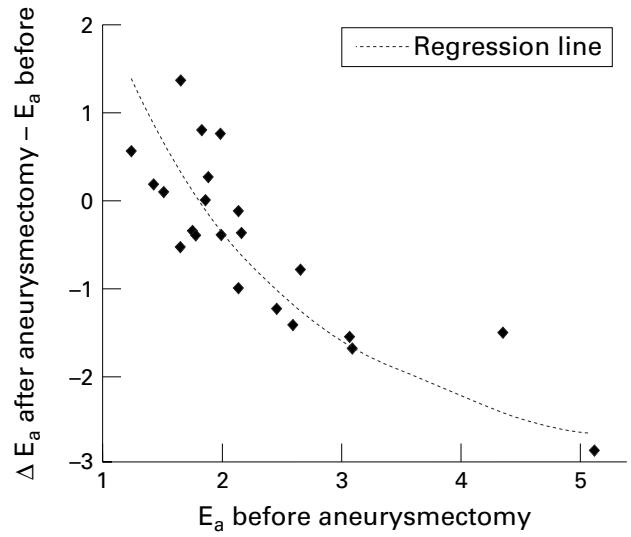

Figure 2 Relation between postoperative changes in effective arterial elastance (Ea) and preoperative values; patients with higher Ea before surgery showed the greatest reduction $(r=0.84 ; p<0.0001)$.

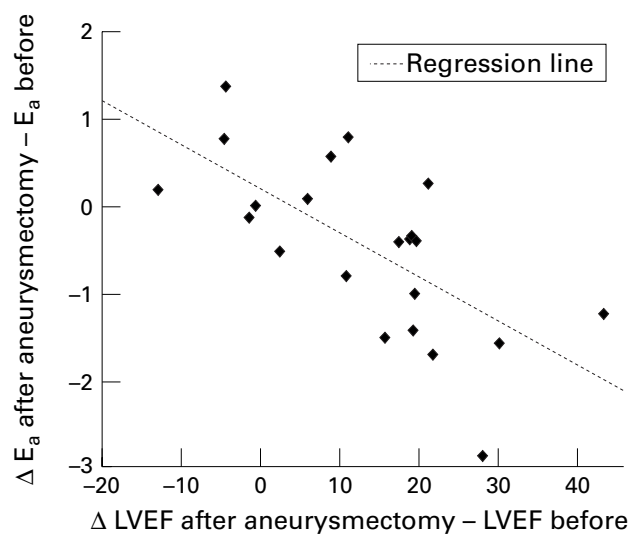

Figure 3 Relation between the postoperative changes in effective arterial elastance (Ea) and left ventricular ejection fraction (LVEF). Patients with the greatest increase in $L V E F$ showed the greatest reduction in $E a(r=0.67$ $p<0.0001$ ).
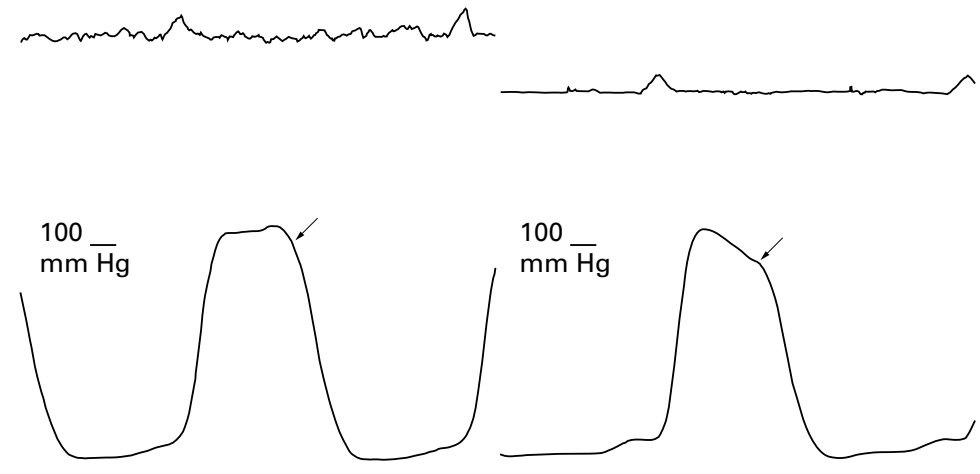

Figure 4 Original tracings of left ventricular pressure in a single case before (left) and after surgery (right). Tracings are displayed at $50 \mathrm{~mm} / \mathrm{s}$ to show their morphology better. The arrows indicate the end systolic pressures.

Table 3 Analysis of left ventricular pressure before and after surgery ejection fraction $(r=0.67, \mathrm{p}<0.001$; fig 3)). Emax and chamber mechanical efficiency increased significantly after surgery.

Analysis of high fidelity left ventricular pressure tracings showed that, after surgery, t-peak decreased from 237 (39) to 191 (41) ms $(\mathrm{p}<0.0001)$ and tmax decreased from 349 (47) to 312 (30) ms $(\mathrm{p}<0.002)$. Also $\mathrm{t}-\mathrm{dP} / \mathrm{dtmax}$ and $\tau$ decreased, without significant changes in maximum left ventricular systolic pressure, $\mathrm{dP} / \mathrm{dtmax}$, or $\mathrm{dP} / \mathrm{dtmin}$ (table 3). Morphological changes in left ventricular pressure tracings were observed after surgery in all patients: thus while left ventricular pressure waves were characterised by a delayed maximum systolic peak and a slow decay during relaxation before surgery, they showed an earlier systolic peak and a faster decay during relaxation after the procedure (fig 4 ).

\section{Discussion}

Patients with postinfarction left ventricular anterior aneurysm had severely depressed left ventricular function, with a marked increase in chamber volumes, reduced ejection fraction, low Emax, and low mechanical efficiency. Preoperative Ea was increased and comparable to values found in patients with idiopathic dilated cardiomyopathy and congestive heart failure. ${ }^{16}$ According to the ventriculoarterial coupling theory, these patients had a mismatch between left ventricular function and arterial impedance.

Endoventricular patch plasty reconstructive surgery for left ventricular aneurysm produced marked changes in chamber volumes: postoperative EDVI became smaller than preoperative ESVI and the reduction in ESVI was even greater. The marked postoperative reduction in EDVI was associated with a decrease in end diastolic pressure, indicating a decrease in left ventricular preload. The lack of postoperative changes in stroke work and stroke volume, in the presence of improved ejection fraction and decreased Ea, further confirms the role played by left ventricular volume decrease. A similar haemodynamic pattern has recently been observed in patients with heart failure after the administration of a potent venous and arterial vasodilator drug with mild positive inotropic effects. $^{6}$

Left ventricular pump function improved after surgery, following Starling's law (maintenance of the same stroke work with a decreased preload). Further evidence of this improvement is the marked increase in mechanical efficiency and the mild increase in Emax. The higher Emax showed by the "reconstructed" left ventricle appeared to be a result of the sharp reduction in ESVI, which was not associated with significant changes in $\mathrm{V}_{0}$.

\begin{tabular}{|c|c|c|c|c|c|c|c|c|}
\hline & $S P(m m H g)$ & t-peak (ms) & $\begin{array}{l}d P / d t m a x \\
(m m H g / s)\end{array}$ & $t-d P / d t m a x$ (ms) & $E S P(m m H g)$ & $\operatorname{Tmax}(m s)$ & $\begin{array}{l}\text { dP/dtmin } \\
(\mathrm{mm} \mathrm{Hg} / \mathrm{s})\end{array}$ & $\tau(m s)$ \\
\hline Preoperative & $126(15)$ & 237 (39) & $1620(787)$ & $121(16)$ & $125(16)$ & $349(47)$ & $1310(458)$ & $51(18)$ \\
\hline After surgery & $118(23)$ & $191(41)$ & $1710(493)$ & $102(20)$ & $111(22)$ & $312(30)$ & $1246(314)$ & $42(7)$ \\
\hline p Value & NS & 0.0001 & NS & 0.003 & 0.02 & 0.002 & NS & 0.02 \\
\hline
\end{tabular}

Values are mean $(\mathrm{SD})$

$\mathrm{dP} / \mathrm{dtmax}$ and $\mathrm{dP} / \mathrm{dtmin}$, maximum rate of rise and fall of left ventricular pressure; ESP, end systolic pressure; SP, maximum systolic pressure; $\mathrm{t}-\mathrm{dP} / \mathrm{dtmax}$, time to $\mathrm{dP} / \mathrm{dtmax}$; $\mathrm{t}$-peak, time interval between left ventricular pressure upstroke and SP; tmax, time to Emax; $\tau$, time constant of pressure decline. 

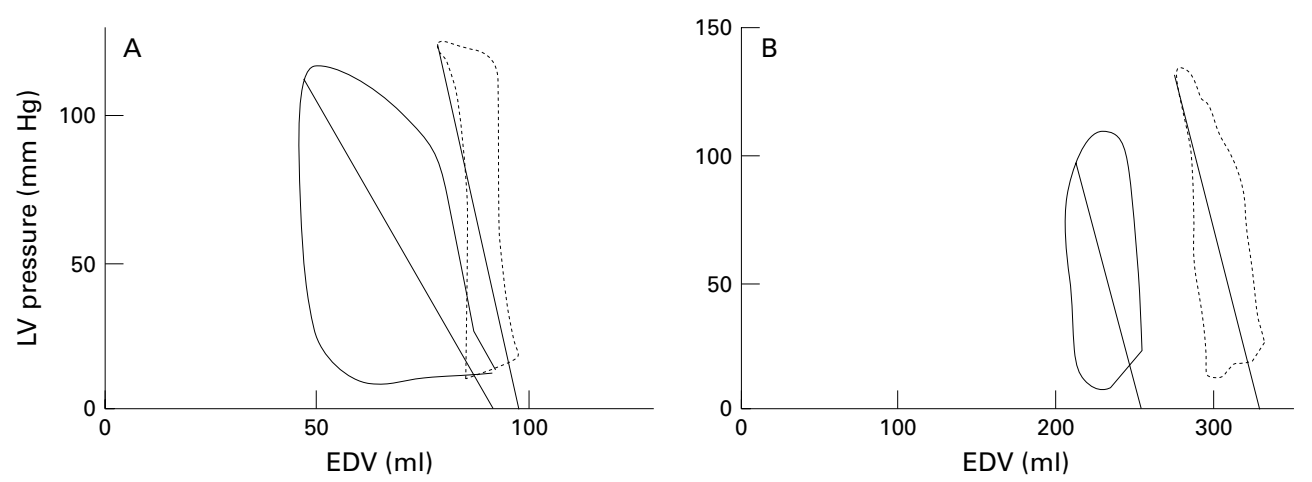

Figure 5 Pressure-volume loops in a single case before and after endoventricular patch plasty. Straight lines indicate the Emax and Ea slopes. Emax increased slightly (from 1.3 to $1.63 \mathrm{~mm} \mathrm{Hg} / \mathrm{ml}^{2} \mathrm{~m}^{2}$ ), while Ea decreased (from 1.64 to 1.41 $\mathrm{mm} \mathrm{Hg} / \mathrm{ml}$ ). SV did not change (from 69 to $71 \mathrm{ml}$ ), neither did $V_{0}$ (from -16.7 to $23.3 \mathrm{ml}$ ). End systolic pressure decreased (from 112.85 to $100.0 \mathrm{~mm} \mathrm{Hg}$ ). Note the different time of maximum systolic pressure before and after surgery.

The absence of significant changes in $\mathrm{V}_{0}$ is not in keeping with the non-physiological two compartment chamber model developed for acute regional ischaemia. ${ }^{17}$ In this experimental model of regional dyssynergy induced by acute ischaemia, a rightward shift of the end systolic pressure-volume relation with an increase in $\mathrm{V}_{0}$ was observed. On the other hand, the clinical applicability of this model was questioned by the investigators themselves. ${ }^{17}$ Moreover, the clinical setting in which we analysed ESPVR was that of a chronic left ventricular aneurysm, which is a fibrous scar with elastic properties that are not comparable to those of a "bulge" caused by acute ischaemia. We cannot exclude the possibility that the single beat method adopted to evaluate ESPVR might have introduced a large scatter of $\mathrm{V}_{0}$ volumes. Indeed, this method has never been validated against any previous conventional method in critically ill patients such as ours, in whom load manipulation was not recommended. Furthermore, in computing ESPVR, we adopted a sampling rate of $50 \mathrm{~Hz}$ (which was determined by the angiographic method) and this might have introduced an even greater scatter of $\mathrm{V}_{0}$ values. However, in our opinion, a degree of uncertainty over the $\mathrm{V}_{0}$ measurement did not detract from the validity of our conclusions, which were supported by analysis of independent haemodynamic variables such as $\mathrm{dP} / \mathrm{dt}$, left ventricular volumes and ejection fraction, arterial elastance, and left ventricular pressure.

Aneurysmectomy, with the accompanying abrupt reduction of left ventricular chamber volume, offered a unique opportunity to study the effects of a sharp reduction in left ventricular afterload-to an extent otherwise not achievable in clinical conditions.

After surgery, arterial elastance decreased because of a significant decrease in end systolic volume, in the absence of significant changes in stroke volume; end systolic pressure also decreased, while systolic and mean arterial pressures did not change significantly. Analysis of high fidelity left ventricular pressure tracings offered an explanation for this result: after surgery, the left ventricular pressure wave was characterised by an earlier systolic peak and an earlier and faster pressure decay, resulting in a lower end systolic pressure (figs 4 and 5). We can confidently assume that the structural characteristics of the aorta and the great arteries did not change after the surgical procedure, and no changes in peripheral vascular resistance were documented. Thus in the absence of changes in heart rate and stroke volume, the change in shape of the left ventricular pressure waveform had to be related to changes in left ventricular contraction - that is, to an increase in left ventricular shortening velocity which has been described after experimental reduction in afterload $^{1819}$ and to a more advantageous load sequence $e^{20-22}$ induced by preload reduction.

It is probable that the intrinsic left ventricular inotropic state did not improve, as indicated by the small increase in Emax and the lack of changes in $\mathrm{dP} / \mathrm{dtmax}$. Isovolumic indices of contractility, such as $\mathrm{dP} / \mathrm{dtmax}$, are known to show little if any change in response to changes in loading conditions. ${ }^{23}$ Moreover, no patient was on inotropic drugs at the time of postoperative catheterisation, and a contractility increase due to myocardial revascularisation would have played a minor role, as the median interval between myocardial infarction and surgery was longer than 12 months, and the same pattern of changes in systolic pressure was observed in six patients with single vessel disease (patients $4,8,11,15,19$, and 20) who did not have bypass grafting in territories remote from that of the excised aneurysmal sac. On the other hand, myocardial contraction may have improved as a result of load changes in non-ischaemic regions remote from the aneurysm, as we showed. ${ }^{24}$

As to the second hypothesis-that is, a changed load sequence - this is in keeping with the experimental data gathered in intact animals, isolated hearts, and papillary muscles, that preload reduction also improves left ventricular function by improving relaxation. ${ }^{25}$ The same pathophysiological mechanism has been postulated to explain the favourable effects of mixed vasodilators in clinical heart failure. Indeed, in our study $\tau$ decreased after surgery, indicating improved left ventricular relaxation.

Some of our data suggest that the more severe the preoperative mismatch between arterial elastance and left ventricular function, the greater the "afterload dependence" of left ventricular function and the greater the advantage of aneurysmectomy. In fact, the postop- 
erative decrease in Ea was related to its preoperative value, and the patients with higher preoperative Ea and a greater postoperative increase in ejection fraction had the most marked postoperative decrease in Ea.

\section{CONCLUSION}

After EVPPR, ventriculoarterial coupling improved. The ratio between arterial and ventricular elastance decreased after surgery, mainly because of the greater decrease in arterial elastance than the lesser increase in ventricular elastance. The decrease in arterial elastance appeared to be related mainly to a reduction in end systolic pressure due to changes in the intraventricular pressure waveform. In the absence of changes in heart rate, stroke volume, and peripheral vascular resistance-and assuming only minor changes in inotropic state and in the structural characteristics of the arterial wall-we believe that these changes in the intraventricular pressure contour mainly reflect loading sequence changes induced by the patch plasty reconstruction.

1 Sunagawa K, Maugham WL, Burkhoff D, et al. Left ventricular interaction with arterial load studied in isolated canine ventricle. Am $\mathcal{F}$ Physiol 1983;245:H773-80.

2 Sunagawa K, Maugham WL, Sagawa K. Optimal arteria resistance for the maximal stroke work studied in isolated canine left ventricle. Circ Res 1985;56:586-95.

3 Burkhoff D, Sagawa K. Ventricular efficiency predicted by an analytical model. Am f Physiol 1986;250:R1021-7.

4 Ishizaka S, Asanoi H, Kameyama T, et al. Ventricular load optimization by inotropic stimulation in patients with heart optimization by inotropic stimulation. Int 7 Cardiol 1991;31:51-8.

5 Ishihara H, Yokota M, Sobue T, et al. Relation between ventriculoarterial coupling and myocardial energetics in patients with idiopatic dilated cardiomyopathy. 7 Am Coll patients with idiopatic

6 Feldman MD, Pak PH, Wu CC, et al. Acute cardiovascular effects of OPC-18790 in patients with congestive heart effects of OPC-18790 in patients with congestive heart
failure. Time- and dose-dependence analysis based on failure. Time- and dose-dependence analysis based

7 kressure-volume relations. Circulation 1996;93:474-83. optimization by unloading therapy in patients with heart failure. 7 Am Coll Cardiol 1991;17:199-207.
8 Sesto M, Schwarz F, Thiedernamm KU, et al. Failure of Sesto M, Schwarz $\mathrm{F}$, Thiedernamm KU, et al. Failure of aneurysmectomy to impro

9 Di Donato M, Barletta G, Maioli M, et al. Early hemodynamic results of left ventricular reconstructive surgery for anterior wall left ventricular aneurysm. Am f Cardiol 1992;69:886-90.

10 Dor V, Montiglio F, Coste P, et al. Left ventricular shape changes induced by aneurysmectomy with endoventricular circular patch plasty reconstruction. Eur Heart $\mathcal{f} 1994 ; 15$ : 1063-9.

11 Dor V, Saab M, Coste P, et al. Left ventricular aneurysm: a new surgical approach. Thorac Cardiovasc Surg 1989;37: 11-19.

12 Chapman CB, Baker O, Reynolds J, et al. Use of biplane cinefluorography for measurement of ventricular volume. Circulation 1958;18:1105-17.

13 Weiss JL, Frederiksen JW, Weisfeldt ML. Hemodynamic determinants of the time-course of fall in canine left determinants of the time-course of fall in can
ventricular pressure. 7 Clin Invest 1976;58:751-60.

14 Senzaki H, Chen-Huan C, Kass D. Single beat estimation of end-systolic pressure-volume relation in humans. Circulation 1996;94:2497-506.

15 Rooke GA, Feigl EO. Work as correlate of canine left ventricular oxygen consumption and the problem of oxygen wasting. Circ Res 1982;50:273-86.

16 Asanoi H, Sasayama S, Kameyama T. Ventriculoarterial coupling in normal and failing heart in humans. Circ Res 1989;65:483-93.

17 Sunagawa K, Maughan WL, Sagawa K. Effect of regional ischemia on left ventricular end-systolic pressure-volume relationship of isolated canine hearts. Circ Res 1983;52. $170-8$.

18 Suga H, Sagawa K, Shoukas AA. Load independence of the instantaneous pressure-volume ratio of the canine left veninstantaneous pressure-volume ratio of the canine left venCirc Res 1973;32:314-22.

19 Spann JF, Bove AA, Natarajan G, et al. Ventricular performance, pump function and compensatory mechanisms in patients with aortic stenosis. Circulation 1980;62:576-81.

20 Hori $M$, Inoue $M$, Kitakaze $M$, et al. Loading sequence is a major determinant of afterload-dependent relaxation in intact canine heart. Am F Physiol 1985;249:H747-754.

21 Ishikaza S, Asanoi H, Wada O, et al. Loading sequence plays an important role in enhanced load sensitivity of left ventricular relaxation in conscious dogs with tachycardiainduced cardiomyopathy. Circulation 1995;92:3560-7.

22 Gillebert TC, Leite-Moneira AF, De Hert SG. Relaxationsystolic pressure relation. A load-independent assessment

3 Quinones MA Contractility. Circulation $\mathrm{JK}$. Influence of acute changes in preload, afterload, contractility state and heart rate on ejection and isovolumic indices of myocardial contractility in man. Circulation 1976;53:293-302.

24 Di Donato M, Sabatier M, Toso A, et al. Regional myocardial performance of non-ischaemic zones remote from anterior wall left ventricular aneurysm. Effects of aneurysanterior wall left ventricular aneurysm. Effe

25 Weber KT, Janicki JS, Hunter WC, et al. The contractile behavior of the heart and its functional coupling to the circulation. Prog Cardiovasc Dis 1982;42:375-400. 